\title{
Experiência lúdica de promoção de alimentação saudável no ambiente escolar: satisfação e aprendizado dos estudantes
}

\begin{abstract}
Resumo
O objetivo desse estudo foi analisar a satisfação e o aprendizado dos escolares participantes de uma experiência lúdica de promoção nos hábitos alimentares saudáveis. A intervenção em análise foi desenvolvida com alunos de 6 a 14 anos, de uma escola municipal de Belo Horizonte, Minas Gerais, e apresentou duração de sete meses. Oficinas educativas e culinárias foram desenvolvidas, com cunho lúdico. O processo de avaliação foi realizado quatro meses após a finalização das atividades por meio de uma "roda de conversa", pautada em um roteiro estruturado submetido à análise de conteúdo. O tamanho amostral considerou a saturação do conteúdo obtida. Participaram do estudo 30 alunos, 58,6\% do sexo feminino, com média de idade de 9,6 (7,0-11,0) anos. A satisfação com as atividades foi identificada por meio de comentários como "Eu gostei de tudo muito mais, eu gostei da nutrição, das historinhas, das comidas" e "Porque de vez em quando a gente não sabia o que comer e comia muita besteira, e agora a gente sabe o que não podemos". As oficinas culinárias foram destacadas pela amostra: "Eu adorei, eu também. Tenho vontade de fazer de novo". O aprendizado foi verificado pelos comentários referente aos grupos alimentares "Eu aprendi que o iogurte é derivado de leite..." e citação dos conceitos gerais sobre alimentação e saúde. As ações lúdicas educativas no ambiente escolar despertaram satisfação dos participantes e incentivaram a construção de conhecimentos sobre alimentação e nutrição.
\end{abstract}

Palavras-chave: Adolescente. Alimentação escolar. Criança. Educação alimentar e nutricional. Hábitos alimentares.

\begin{abstract}
The aim of this study was analyzed the satisfaction and learning of schoolchildren participating of a playful experience of promotion of healthy eating habits. The intervention, that lasted seven months, was developed with students from 6 to 14 years old of a municipal school of Belo Horizonte, Minas Gerais. It was composed of education and cooking workshops. The evaluation process was conducted four months after the completion of activities through a "conversation circle", based on a structured questionnaire submitted to content analysis. The sample size considered the saturation of the obtained content. Thirty students, 58.6\% female, participated of study with a mean age of 9.6 (7.0 - 11.0). Satisfaction with the activities was marked with comments like "I liked everything so much, I liked the nutrition, stories, meals" and "For once in a while we did not know what to eat and eat a lot of nonsense, and now we know what we can not." Culinary workshops were highlighted by the sample: "I loved it, me too. I want to do it again. "Learning was verified by the comments regarding the food groups "I learned that yogurt is derived from milk ...." and quote the general concepts about food and health. The playful experience in school environment awakened satisfaction of the participants and encouraged the construction of knowledge about food and nutrition.
\end{abstract}

Keywords: Adolescent. School feeding. Child. Food and nutrition education. Food habits.

DOI: $10.15343 / 0104-7809.201640013850$

\footnotetext{
* Departamento de Nutrição, Universidade Federal de Minas Gerais, Belo Horizonte - MG, Brasil

** Departamento de Nutrição, Universidade Federal de Minas Gerais, Belo Horizonte - MG, Brasil luanacs@ig.com.br

Os autores declaram não haver conflitos de interesse.
} 


\section{INTRODUÇÃO}

A complexa formação dos hábitos alimentares se inicia na infância, sendo que nos primeiros anos de vida, o padrão alimentar se restringe à escolha dos pais, responsáveis por determinar quais alimentos serão oferecidos para as crianças. Com o início da vida escolar e o convívio com outras pessoas, novos alimentos e preparações são incluídos no cotidiano infantil. Assim, a consolidação dos hábitos é um processo gradativo, ocorrendo à medida que a criança cresce até o momento em que ela é capaz de definir os alimentos que farão parte do seu comportamento alimentar ${ }^{1-3}$.

Nesse sentido, percebe-se a importância de atividades de educação alimentar e nutricional na promoção de práticas alimentares saudáveis desde a infância, visto que, além de promover o crescimento ideal e o desenvolvimento cognitivo, podem contribuir para prevenção de desvios nutricionais como a obesidade e suas comorbidades consequentes ${ }^{4,5}$.

A educação alimentar e nutricional se refere a um processo contínuo e duradouro de aprendizagem, o qual propicia o desenvolvimento amplo do sujeito e possibilita a aquisição de habilidades individuais, tornando-o capaz de decidir sobre suas escolhas alimentares, além de incentivar a adoção de um comportamento saudável em suas famílias ${ }^{3,4}$. As estratégias de intervenção direcionadas às crianças e adolescentes precisam oportunizar a construção conjunta de conhecimento, incentivando-os a participar de maneira ativa² ${ }^{2}$

Deste modo, o caráter prescritivo e normativo com foco central na mera transmissão de informações, bem como o uso de abordagens tradicionais que consideram o participante como simples receptor de conhecimento e não promovem um diálogo reflexivo devem ser abolidos ${ }^{4,5}$. Torna, então, necessário, desenvolver abordagens e recursos ativos e problematizadores, como o uso de métodos lúdicos como dinâmicas e jogos educativos. Estes podem favorecer a construção de conhecimento, sobretudo para o público infanto-juvenil1, tendo em vista oportunizar a adesão, troca de ideias e experiências, além de explorar a criatividade e imaginação dos participantes ${ }^{6,7,8}$.
Ao considerar crianças e adolescentes, o ambiente escolar consiste em um local estratégico para o desenvolvimento das atividades de educação alimentar e nutricional por caracterizar-se como um espaço de aprendizagem e permitir compartilhamento de hábitos e preferências alimentares durante as refeições ali realizadas e oportunidade pedagógica associada ${ }^{5,9,10}$.

Dessa maneira, o presente estudo objetivou analisar a satisfação e o aprendizado das crianças e adolescentes, ao participarem de uma experiência lúdica de promoção de alimentação saudável no âmbito escolar.

\section{METODOLOGIA}

\section{Tipo de estudo e casuística}

Trata-se de um estudo com enfoque qualitativo desenvolvido quatro meses após a finalização das atividades de uma intervenção nutricional. Essa, foi realizada entre abril e outubro de 2010 com 156 alunos matriculados do $1^{\circ}$ ao $6^{\circ}$ ano do Ensino Fundamental, com faixa etária entre 6 e 14 anos, participantes do programa Escola Integrada de uma Escola Municipal de Belo Horizonte, Minas Gerais.

\section{Programa Escola Integrada}

O programa Escola Integrada encontra-se implantado em 131 escolas da rede pública municipal de Belo Horizonte, atendendo 33.000 crianças e adolescentes matriculados no Ensino Fundamental. As escolas são responsáveis pelo desenvolvimento de ações articuladas com programas já existentes na comunidade, de forma a promover novas atividades que atendam ao projeto pedagógico da escola e, assim, favorecer a melhoria da aprendizagem de seus alunos ${ }^{10}$.

Através do programa, há uma ampliação do tempo diário escolar disponibilizado para as práticas educativas multidisciplinares. Os alunos inscritos permanecem nos períodos da manhã e tarde na escola ou nos ambientes disponíveis para as atividades, como clubes, igrejas, museus e quadras, sendo garantidas nove horas diárias de ações. Essas abrangem aulas de língua estrangeira, auxílio no dever de 
casa, oficinas com temas variados e prática de diversos tipos de esportes e brincadeiras ${ }^{10}$.

\section{Intervenção Nutricional}

No âmbito do programa Escola Integrada, foram inseridas as atividades de educação alimentar e nutricional, ministradas por estudantes de graduação e pós-graduação em Nutrição da Universidade Federal de Minas Gerais (UFMG), com a supervisão de docentes da instituição. No total, foram realizados 15 encontros com cada turma, dos quais oito foram oficinas educativas, seis oficinas culinárias e uma excursão a um teatro.

A primeira oficina visou introduzir conceitos nutricionais gerais, incluindo os grupos alimentares ${ }^{11}$ por meio da pirâmide alimentar, instrumento simples, acessível e de fácil assimilação ${ }^{12}$. Após essa atividade inicial, foram aplicadas oficinas educativas e culinárias sobre os grupos, havendo ainda um encontro final com o intuito de rever o conteúdo abordado. Ressalta-se que as metodologias foram diferenciadas segundo a faixa etária dos escolares, dividindo-se as turmas em dois grupos: $1^{\circ}$ ao $3^{\circ}$ ano e $4^{\circ}$ ao $6^{\circ}$ ano (Quadro 1 ).

Todas as oficinas abrangeram uma exposição dialogada inicial para introdução teórica do grupo alimentar a ser trabalhado e foram complementadas com dinâmicas e jogos diversos relacionados ao tema abordado. Após intervalo de aproximadamente dez dias, uma oficina culinária relativa ao grupo alimentar foi executada, permitindo o preparo da receita pelo próprio aluno, de forma cooperativa e divertida a fim de facilitar o processo de recordação e construção do conteúdo, além de favorecer a troca de experiências. As oficinas educativas foram subsidiadas por materiais do Ministério da Saúde ${ }^{13,14}$ e da Secretaria Municipal de Segurança Alimentar e Nutricional de Belo Horizonte $^{15}$. As receitas foram baseadas em livros de culinária direcionados ao público infantil, sendo previamente testadas e adaptadas, quando necessário.

A metodologia lúdica empregada foi adequada conforme a faixa etária das turmas. Para as turmas do $1^{\circ}$ ao $3^{\circ}$ ano, o conteúdo teórico dos grupos alimentares foi abordado por meio de teatro de fantoches com vários personagens confeccionados em espuma (crianças, fadas, animais, frutas e vegetais) para propiciar maior interação com as crianças. Já para as crianças das turmas do $4^{-}$ao $6^{\circ}$ ano, foram organizadas "rodas de conversa" em que, por meio de bate-papo discutiase o grupo alimentar e a partir de material ilustrativo (banner e cartilhas) incentivava-se a construção de paródias de músicas populares com conteúdo referente ao assunto abordado. A equipe de apoio contava com uma musicista e violão.

Posteriormente à exposição teórica de cada grupo alimentar, por meio do teatro de fantoches ou das rodas de conversa, as crianças eram divididas em quatro grupos, sendo cada um orientado por um membro da equipe de Nutrição. Dessa forma, cada grupo iniciava a atividade participando de uma dinâmica e, após o término desta, era deslocada para a dinâmica que outra equipe estava desenvolvendo e assim sucessivamente, de modo a formar um ciclo no qual as crianças participassem das todas as atividades propostas.

Dentre os jogos e dinâmicas citados podese exemplificar as características de alguns: a) Jogo da memória: visualização de peças com ilustrações de todos os grupos alimentares com o objetivo de encontrar o par da figura retirada, ou o par do alimento com uma preparação que utiliza aquele alimento; b) Dinâmica da "fruta-quente": uma brincadeira de roda na qual houve a passagem de uma fruta por cada escolar ao som de uma música, até parar em um deles, para que este respondesse uma pergunta sobre alimentação; c) Dominó: combinação de peças entre si, de acordo com a ilustração do alimento que apresentava; d) Jogo de pescaria: pescar as réplicas em espuma dos alimentos do grupo que estava sendo estudado na oficina em questão; e) Jogos de cartas incluindo o jogo "Super Trunfo", que consistia na competição com base na composição nutricional de alguns alimentos; f) "Jogos de tabuleiro, como "Campo Minado", com perguntas e comandos; Jogo "Quem sou eu", de adivinhação e etc.

Em relação às oficinas culinárias, os alunos também foram subdivididos em grupos compostos de aproximadamente seis crianças. Cada grupo contou com o apoio de uma monitora para auxiliá-los nas preparações e na recordação sobre o conteúdo teórico 
explanado na oficina educativa. Após breve exposição sobre o assunto, os ingredientes das receitas foram disponibilizados aos grupos, de forma que cada aluno participasse de alguma etapa da preparação. Ressalta-se que as receitas escolhidas eram de fácil preparo e, em grande parte, não levavam ingredientes que precisavam ser preparados com a utilização de fogão ou outros equipamentos de difícil acesso pelas crianças. Após a preparação, os alunos consumiam os alimentos preparados.

Cada oficina apresentou duração aproximada de uma hora e trinta minutos e foi composta por no máximo 25 alunos do mesmo ano letivo. $\mathrm{O}$ tempo previsto para a realização das atividades foi estipulado de forma a permitir o adequado desenvolvimento das oficinas propostas, sem favorecer a dispersão dos alunos. As atividades foram aplicadas com base no tamanho amostral estudado, sendo realizadas 14 oficinas com cada turma (do $1^{\circ}$ ao $6^{\circ}$ ano), totalizando 84 oficinas.

Destaca-se que todas as oficinas, tanto as educativas quanto as culinárias, foram implementadas a partir de um roteiro prédefinido, incluindo a previsão de todas as falas com os participantes. Os itens lúdicos (teatro, paródias, jogos, cartilhas, entre outros) foram, em sua maioria, confeccionados pela própria equipe de pesquisa.

Após o final das atividades, os escolares foram convidados a assistir a uma peça de teatro "Alice no país das gostosuras" apresentado por um grupo profissional contratado pela pesquisadora responsável. A peça foi executada em um teatro municipal e abordava a importância da alimentação saudável com uma linguagem acessível aos participantes. Adicionalmente, todos os escolares receberam uma cartilha contendo as receitas das preparações trabalhadas, a fim de recapitulá-las, e possibilitar a transmissão aos pais dos conceitos aprendidos.

\section{Coleta de informações}

A avaliação da intervenção foi realizada através de uma discussão, no formato "roda de conversa" 16, quatro meses após a conclusão das atividades. Tal período de tempo entre o fim da intervenção e o processo avaliativo justificase devido às atividades de educação alimentar e nutricional terem se encerrado próximo ao fim do semestre letivo, o que inviabilizou a avaliação imediata. Entretanto, cumpre-salientar que esse período de tempo permitiu identificar o que realmente foi aprendido pelos escolares e não a aquisição simultânea de conteúdo.

A discussão foi norteada por um roteiro estruturado com sete tópicos contemplando aspectos relacionados à construção do conhecimento, aceitação e satisfação em relação aos trabalhos realizados, além de oportunizar críticas e sugestões de temas e atividades para futuros trabalhos de cunho nutricional. Para tal, foram convidados cinco alunos por vez.

Participaram da "roda de conversa" 30 alunos, representando $18,6 \%$ da amostra da intervenção. Os participantes foram selecionados após um sorteio aleatório, sendo utilizada a metodologia de saturação do conteúdo para finalização do procedimento de seleção.

Em termos organizacionais, a "roda de conversa" foi iniciada pela apresentação dos participantes, seguida pelo questionamento se os alunos se lembravam da equipe responsável pela intervenção e das atividades de educação alimentar e nutricional realizadas. Em seguida, foi avaliada a construção de conhecimento por meio das oficinas, destacando-se os grupos constituintes da pirâmide alimentar ${ }^{12}$. Por fim, averiguou-se a satisfação em relação às atividades, com espaço para críticas e sugestões para ações futuras.

Os diálogos com cada grupo foram gravados e conduzidos por um facilitador, acompanhado por um observador responsável pela gravação. Ressalta-se que cada "roda", com duração aproximada de 13 minutos, foi mediada pelo mesmo facilitador de forma a padronizar a condução da entrevista.

Posteriormente, o material foi transcrito e categorizado de acordo com o ano letivo das crianças eadolescentes e em relação às temáticas abordadas no questionário. O conteúdo foi, então, descrito e interpretado por meio da análise de conteúdo, método compreendido como um conjunto de técnicas de pesquisa que apresentam o objetivo de descrever o sentido de um determinado documento, visando à compreensão do significado das mensagens

\section{1}


através da inferência e interpretação ${ }^{17,18}$.

Aspectos éticos

O presente estudo foi aprovado pelo Comitê de Ética em Pesquisa da UFMG (ETIC 009/09) e pela Prefeitura Municipal de Belo Horizonte (CAAE 0011.0.410.203-09) de acordo com as normas estabelecidas pelo Conselho Nacional de Saúde.

As crianças e adolescentes aceitaram participar voluntariamente da pesquisa e foram autorizadas por seus pais ou responsáveis legais mediante assinatura do Termo de Consentimento Livre e Esclarecido.

\section{RESULTADOS E DISCUSSÃO}

Os participantes $(n=30), 58,6 \%$ do sexo feminino, apresentaram média de idade de 9,6 (7,0 - 11,0) anos e demonstraram amplo interesse pela avaliação realizada. A divisão em subgrupos de no máximo cinco alunos, provavelmente evitou possíveis dispersões que pudessem atrapalhar o processo de avaliação, além de incitar e favorecer a participação ${ }^{19}$.

Quadro 1 - Caracterização das atividades de intervenção realizadas com os escolares, Belo Horizonte - MG, 2011.

\begin{tabular}{|c|c|c|}
\hline \multirow[t]{2}{*}{ Oficinas, objetivos e temáticas } & \multicolumn{2}{|l|}{ Atividades } \\
\hline & $1^{\circ}$ ao $3^{\circ}$ ano & $4^{\circ}$ ao $6^{\circ}$ ano \\
\hline \multicolumn{3}{|l|}{$\begin{array}{l}\text { Oficina introdutória: Alimentação } \\
\text { saudável }\end{array}$} \\
\hline $\begin{array}{l}\text { Introduzir a pirâmide alimentar; } \\
\text { ressaltar a necessidade de hábitos } \\
\text { alimentares saudáveis por meio do } \\
\text { consumo de alimentos variados }\end{array}$ & $\begin{array}{l}\text { Vídeo educativo (Nutriamigos); } \\
\text { Dinâmica: montagem da pirâmide } \\
\text { alimentar; } \\
\text { Colorir e ligar desenhos de } \\
\text { alimentos da pirâmide }\end{array}$ & $\begin{array}{l}\text { Dinâmica: montagem da pirâmide } \\
\text { alimentar; Exibição e discussão de } \\
\text { filme ("Os sem floresta") }\end{array}$ \\
\hline \multicolumn{3}{|l|}{ Grupo dos cereais, pães e massas } \\
\hline $\begin{array}{l}\text { Abordar os alimentos pertencentes } \\
\text { a esse grupo e principais nutrientes, } \\
\text { destacando a importância destes } \\
\text { para a saúde }\end{array}$ & $\begin{array}{l}\text { Oficina educativa: Teatro de } \\
\text { fantoches; Jogo da memória de } \\
\text { desenhos de cereais; Jogo de cartas } \\
\text { (Quiz cereais); Colorir desenhos de } \\
\text { alimentos do grupo } \\
\text { Oficina culinária: Banana, aveia e } \\
\text { mel }\end{array}$ & 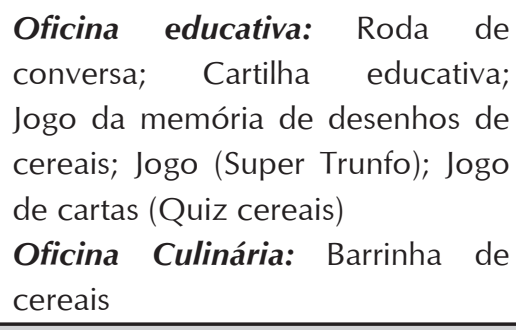 \\
\hline \multicolumn{3}{|l|}{ Grupo das frutas } \\
\hline $\begin{array}{l}\text { Apresentar os alimentos que } \\
\text { compõem esse grupo, os principais } \\
\text { nutrientes e a importância destes } \\
\text { para a saúde; } \\
\text { Apresentar a necessidade e as } \\
\text { formas corretas de higienização; } \\
\text { Estimular o consumo desses } \\
\text { alimentos }\end{array}$ & $\begin{array}{l}\text { Oficina educativa: Teatro de } \\
\text { fantoches; Jogo de dominó, } \\
\text { contendo ilustrações de frutas; Jogo } \\
\text { quebra-cabeça; Jogo de tabuleiro } \\
\text { das frutas } \\
\text { Oficina culinária: Vitamina de } \\
\text { frutas }\end{array}$ & $\begin{array}{l}\text { Oficina educativa: Roda de } \\
\text { conversa; Cartilha educativa; } \\
\text { Paródia (Eu gosto muito de fruta); } \\
\text { Jogo (Quem sou eu?); Jogo (Fruta- } \\
\text { quente); Jogo de tabuleiro das } \\
\text { frutas } \\
\text { Oficina culinária: Salada de frutas }\end{array}$ \\
\hline
\end{tabular}




\section{Grupo das Hortaliças}

Abordar as verduras e legumes Oficina educativa: Teatro de conversa; Cartilha educativa; pertencentes a esse grupo, seus Fantoches; Jogo da memória; Jogo Paródia (Vamos para a feira comprar nutrientes e importância para a quebra-cabeças; Jogo (Encontre as hortaliças); Jogo (Vai comprar qual saúde; Ressaltar a necessidade do hortaliças). hortaliça?); Jogo quebra-cabeça; consumo diário destes; Ressaltar a Oficina culinária: Sanduíche de Jogo (Bingo das hortaliças/caçaimportância da higienização desses "carinha" alimentos palavras)

Oficina culinária: Sanduíche tricolor

\section{Grupo do leite e derivados}

Oficina educativa: Teatro de Oficina educativa: Roda de Abordar o grupo do leite e fantoches; Jogo (Campo Minado); conversa; Cartilha educativa; derivados; Ressaltar os principais nutrientes e sua importância para o crescimento e fortalecimento dos ossos Jogo (Pescaria dos alimentos do Paródia (Leite e derivados eu gosto grupo); Jogo quebra-cabeça de montão); Jogo (Campo Minado); Oficina culinária: logurte natural Jogo (Pescaria dos alimentos do com frutas grupo); Gincana

Oficina culinária: Rocambole aos três queijos

\section{Grupo das carnes e ovos; e grupo} das leguminosas

Apresentar os ovos, os diferentes tipos de carnes e leguminosas; ressaltar as diferenças e semelhanças entre os alimentos desses grupos e a importância dos mesmos
Oficina educativa: Teatro de fantoches; Jogo de artes; Jogo (Montando as leguminosas, carnes e ovos); Jogo de baralho

Oficina culinária: Sanduíche de atum com ervilha e cenoura
Oficina educativa: Roda de conversa; Cartilha educativa; Paródia (Para não ficar com anemia); Jogo (Quem sou eu?); Jogo (A Nutricionista e o expectador inteligente); Jogo de baralho

Oficina culinária: Salpicão super saudável

\section{Grupo dos açúcares e doces; e} grupo dos óleos e gorduras

Oficina educativa: Teatro de

Apresentar os alimentos fantoches; Jogo da memória; Jogo pertencentes a esses grupos, (Super Trunfo); Jogo (Mercado dos ressaltando os benefícios do açúcares); Jogo das figuras: Óleos e consumo e os malefícios da gorduras ingestão exagerada
Oficina culinária: Bombom Bem Bom
Oficina educativa: Roda de conversa; Cartilha educativa; Paródia (Doces devemos evitar); Jogo da memória; Jogo (Super Trunfo); Jogo (Mercado dos açúcares); Jogo (Batata quente)

Oficina culinária: Surpresa de Laranja

\section{Oficina final: Revisão dos grupos -} Pirâmide alimentar

Revisar os grupos que compõem a Roda de conversa e dinâmica; Pirâmide Alimentar, relembrando Jogo (Pescaria); Jogo da memória; os alimentos e seus nutrientes, e a Montagem da pirâmide alimentar importância de uma alimentação em uma folha de papel Roda de conversa e dinâmica; Jogo de baralho (Nutricard); Jogo da memória; Jogo de tabuleiro saudável e variada 
Quando estimulados a recordarem da equipe de nutrição e das atividades educativas ministradas, a maioria dos escolares não apresentou dificuldades conforme demonstrado nas falas: "Lembramos", "Nutricionistas" e "Me ensinou a fazer iogurte". Destaca-se também que os alunos foram capazes de lembrar características físicas das integrantes da equipe, como exemplo: "Só que a V. está um pouquinho diferente"; "Porque o seu olho mudou" e "Da outra com nome..., com olho verde"; além de questionarem a ausência de algumas no dia da avaliação. Tal fato reforça o vínculo desenvolvido entre os alunos e educadores e pode motivar o processo de aprendizagem. Sabe-se que o envolvimento do educador com o aluno é essencial para a construção e o sucesso do ensino, uma vez que possibilita a troca de experiências, emoções e sentimentos, além de valorizar as opiniões e sugestões e dos alunos $^{20,21}$.

A satisfação e o interesse com a intervenção executada pôde ser constatada por meio de afirmações como: "Eu gostei de tudo muito mais, eu gostei da nutrição, das historinhas, das comidas" e "Eu gostei de tudo". Outros comentários podem ser visualizados no (Quadro 2).

Além disso, os estudantes manifestaram o desejo de continuidade das atividades, o que pode ser confirmado por respostas como: "Vai ter de novo nutrição?"; "Vocês não vão dar mais aula para gente não?" e "Queria que vocês voltassem aqui" (Quadro 2). Essas falas relevam a aprovação e demonstram o interesse pelo prosseguimento das ações educativas de cunho alimentar e nutricional, essencial para que novos projetos com esse tema sejam desenvolvidos no ambiente escolar ${ }^{2}$.

Os comitês nacionais e internacionais de nutrição apontam que o envolvimento da escola como agente ativo na transformação é primordial para a qualidade da alimentação infanto-juvenil tendo em vista as prevalências alarmantes de obesidade e outras doenças e agravos não transmissíveis neste ciclo da vida. A escola pode contribuir para esse item por meio da oferta de alimentos saudáveis em seu espaço, mas sobretudo pela sensibilização da necessidade desta temática dentro da comunidade por ela atendida ${ }^{2},{ }^{22}$. Pode-se ainda fomentar a inserção da educação nutricional nos parâmetros curriculares ${ }^{2,5}$, tal como proposto pelo Programa Saúde na Escola (PSE) ${ }^{23}$.

O PSE é uma estratégia de integração da saúde e educação para o desenvolvimento da cidadania e da qualificação das políticas públicas brasileiras, na qual se insere a diretriz "Tratar a saúde e educação integrais como parte de uma formação ampla para a cidadania e o usufruto pleno dos direitos humanos" tendo como um de seus componentes o desenvolvimento de ações de segurança alimentar e promoção da alimentação saudável no ambiente escolar ${ }^{23}$.

Ao indagar sobre quais foram as atividades preferidas pelas crianças e adolescentes, as principais respostas foram: teatro ("bonecos que mexiam e falavam"; "teatro da galinha e do pirulito"); jogos ("memória", "pescaria", "baralho", "espectador inteligente"); paródias ("Eu gosto muito de frutas, isso me faz muito bem, eu gosto de melancia, maçã também, a banana e a uva, goiaba, abacaxi, a laranja e a pêra, o kiwi, todas elas são frutinhas e tem muitos minerais. Ai que delícia, eu quero mais. Fruta também têm vitaminas e não deixa ficar doente, protege a saúde é diferente") (Quadro 2).

Dentre essas atividades citadas, destaca-se a preferência pelo teatro. O uso da dramaturgia, arte pautada na criatividade e aprendizado por meio da descontração e uso da imaginação, consiste em uma estratégia efetiva de educar em saúde, especialmente para o público infantojuvenil, uma vez que o teatro é facilmente assimilável pela faixa etária em estudo e oportuniza, de maneira lúdica, uma reflexão sobre os conhecimentos e expectativas dos participantes em relação ao tema abordado ${ }^{5,7,8}$.

Ressalta-se também a grande aceitação dos escolares em relação às oficinas culinárias, uma vez que mesmo quando questionados sobre outros temas, incluindo as atividades educativas, a maioria das respostas baseou-se nas receitas preparadas nas oficinas. Os alunos demonstraram a preferência por meio de falas como: "Eu amei" e "Eu gostei mais ainda", e alguns, inclusive, relataram o preparo das receitas em casa. Dentre as preparações culinárias mais citadas, encontra-se o "iogurte", "docinho", "hambúrguer" (referente ao sanduíche natural ou "de carinha"), mencionadas em todos os anos letivos, por mais de um aluno (Quadro 2). 
Quadro 2 - Principais respostas dos escolares sobre a satisfação e aprendizado com a intervenção realizada, Belo Horizonte - MG, 2011.

\begin{tabular}{ll}
\hline \multicolumn{2}{l}{ Satisfação geral com a intervenção } \\
\hline \multicolumn{1}{c}{$\mathbf{1}^{\mathbf{0}-\mathbf{3}^{\mathbf{0}} \text { ano }}$} & \multicolumn{1}{c}{$\mathbf{4}^{\mathbf{0}-\mathbf{6}^{\mathbf{0}} \text { ano }}$} \\
\hline "Gostamos" & "Eu gostei demais" \\
-"Eu gostei muito" & - "Gostamos" \\
-"Eu gostei infinito" & -"Eu gostei, a gente comia muito" \\
-"Eu gostei mais infinito" & -"Eu gostei demais" \\
-"Eu gostei mais de 1000" & -"Gostamos" \\
\hline
\end{tabular}

\begin{tabular}{cc}
\hline Satisfação com as oficinas educativas e culinárias \\
\hline $1^{\circ}-3^{\circ}$ ano & $4^{\circ}-6^{\circ}$ ano \\
\hline
\end{tabular}

-"Eu gostei de tudo muito mais, eu gostei da nutrição, "Só de lembrar da vontade de fazer de novo" das historinhas, das comidas"

-"Legal"

-"Fizemos muitas coisas"

-"Eu gostei do teatrinho, gostei mais do teatrinho"

-"Eu gostei daqueles bonecos que mexiam e falavam"

-"Eu gostei de tudo"

-"Eu achei a oficina mais boa foi a do iogurte"

-"Foram uma delícia"

-"Eu gostei daquele pão com não sei o que lá"

-"Eu gostei daqueles peixinhos lá"

-"Eu achei legal, achei bom"

-"Gostei de fazer... esqueci o nome... logurte"

-"Do sanduíche"

-"Eu gostei do jogo"

-"Eu achava bom"

-"Eu gostei do teatrinho da galinha, gostei do teatro do pirulito, que não pode comer muito chiclete"

-"Eu gostei do jogo da memória"

\section{Aprendizado}

$$
1^{\circ} \text { - 3ํano }
$$

-"Melhor ainda (em relação às oficinas culinárias)"

-"Eu achei bom. Eu achei ótimo".

-"Eu adorei, eu também. Tenho vontade de fazer de novo (em relação às oficinas culinárias)"

“É vitamina, salada de frutas, salpicão, hambúrguer, cenoura"

-"Foram muito interessantes"

-"Legais demais"

-"Ajudou a gente demais"

-"Porque de vez em quando a gente não sabia o que comer e comia muita besteira, e agora a gente sabe, o que não podemos"

-"Eu amei"

-"Eu lembro dela melhor, a barrinha de cereal"

-"Eu quero fazer uns negócios lá em casa, uns docinhos, ajudar a minha mãe na hora do aniversário, -"Eu aprendi que tem que ter muita educação, aprendi a fazer culinária e mais muitas coisas" aniversário das meninas, de minhas amigas, no dela, quero ajudar a fazer docinho"

-"Tudinho"

-"Eu aprendi que o iogurte é derivado de leite, do queijo e o requeijão" 
-"Aprendi a fazer docinho, salada"

-"Nem sabia o que o queijo era, eu achava que o queijo era gordura pura, gordura pura. Eu sei fazer, meu avô faz"

-"Gostei mais daquele negócio daquele potinho lá, -"Eu aprendi sobre higiene e alimentação saudável" de iogurte e gostei da historinha também"

-"Que é para comer...feijão"

\author{
-"Deixa eu ver... Arroz!" \\ -"Carne com batata"
}

-"Maçã, salada, um monte de coisa, leite, comer um pouquinho de cada coisa (em relação a como deve ser uma alimentação saudável)"

-"Eu aprendi assim, a gente falou muito sobre a pirâmide, também de alimentar melhor...."

-"Eu aprendi que quando for tem que colocar touca na cabeça e passar álcool na mão"

-"Eu aprendi a fazer comida, a fazer iogurte e -"Quanto comer por dia" brigadeiro..."

-"Fazer vitamina de banana, aprendi a fazer iogurte -"É de fazer vitamina" e salada de fruta"

-"A fazer vitamina de banana, aprendi a fazer iogurte - "Aprendi da música lá" e salada de fruta"

-"Porque tem a gordura que a gente precisa um -"Eu aprendi a me alimentar bem" pouquinho assim

(em relação ao grupo do leite)"

-"Não comer muita fritura, tomar leite faz bem pros dentes e pras unhas"

-“Cheguei em casa eu comi arroz, feijão, carne..."

-"Cálcio (nutriente do leite)"

-"Fazer aquela não sei o que... aquele hambúrguer
lá que nós fez"

"Eu parei de comer bobeira, mas eu ainda como"

- Na aula de culinária, eu aprendi que a gente tem

-"Eu aprendi que a gente pode levar se alimentar muito que comer sempre bem, não ficar comendo direto bala, pirulito, salgadinho"

melhor, comendo os nutrientes certos e também que doce e balas fazem mais mal e a gente tem que se alimentar com os que dão mais força"

-"Tem que escovar de manhã, de tarde e de noite. -"São carne, verdura, legumes, frutas, leguminosas E passar sabonete na mão antes de comer qualquer (alimentos que dão força)" coisa"

-"Eu aprendi que a gente não deve comer muita bobeira, que deve comer só coisa saudável"

-"Aprendi que a gente tem que sempre se alimentar bem no almoço, não comer muitas balas, porque senão a gente vai ficar com cárie, estraga os dentes. Também aprendi que a gente não deve jogar comida fora"

A prática culinária é um hábito constante na vida da população e envolve vários aspectos, não se limitando apenas à execução de uma preparação. Assim, tal atividade facilita o processo de recordação e construção do conteúdo, favorece a troca de experiências e permite o envolvimento dos alunos com a elaboração das preparações, contribuindo para despertar mais interesse para o consumo do produto final, já que manipular e preparar alimentos pode estimular sua ingestão. Nesse contexto, entende-se que o resgate da culinária como uma prática educativa, que valoriza a participação ativa dos indivíduos envolvidos e aprecia a cultura da comunidade, consiste em um instrumento viável para a promoção das práticas da alimentação saudável, sobretudo em tempos em que refeições prontas e 
industrializadas são realizadas em grande quantidade $23,24,25$.

O Guia Alimentar para a População Brasileira reforça esses achados ao apontar como uma de suas diretrizes "Prefira semprealimentos in natura ou minimamente processados e preparações culinárias a alimentos ultraprocessados", de modo a estimular o desenvolvimento, exercício e compartilhamento de habilidades culinárias; além de valorizar o ato de preparar e cozinhar alimentos; e defender a inclusão das habilidades culinárias como parte do currículo das escolas ${ }^{25}$.

No tocante ao aprendizado, destaca-se que os escolares, em sua maioria, se recordaram dos grupos da pirâmide alimentar, citando, muitas vezes, os alimentos pertencentes a determinado grupo (Quadro 2). Ademais, a construção de conhecimento foi identificada por comentários como: "Na aula de culinária, eu aprendi que a gente tem que comer sempre bem, não ficar comendo direto bala, pirulito, salgadinho". Esses achados adquirem relevância tendo em vista a frequente constatação de práticas alimentares inadequadas entre crianças e adolescentes, caracterizando-se pelo consumo insuficiente de alimentos fontes de cálcio e excessivo em sódio, gorduras e açúcares ${ }^{26}$.

Em amostra representativa de alunos do $9^{\circ}$ ano do ensino fundamental de escolas públicas e privadas das 26 capitais brasileiras e do Distrito Federal, verificou-se o consumo regular de alimentos saudáveis como leite $(62,6 \%)$ e feijão $(53,6 \%)$ aproximado dos percentuais de consumo regular de guloseimas (50,9\%). Isso favorece o consumo de micronutrientes aquém dos valores recomendados ${ }^{27}$. Na Europa, dois amplos estudos identificaram, entre crianças e adolescentes (4 a 18 anos) consumo calórico excessivo e inadequação de micronutrientes essenciais ao crescimento e desenvolvimento infantil demandando estratégias de melhoria ${ }^{28}$.

Cumpre ainda destacar que a intervenção revelou um papel importante de formação de multiplicadores tendo em vista as falas dos alunos denotando interesse em transmitir o que foi aprendido para seus familiares. Tal aspecto oportuniza a ampliação da adoção de um comportamento saudável ${ }^{2,25}$ e também foi constatada por outros autores. Em 28 escolas primárias do norte da China, avaliouse o impacto positivo de uma intervenção educativa, inserida no currículo escolar, no consumo de sal de 278 crianças. Os benefícios identificados foram estendidos aos familiares dos participantes ${ }^{29}$.

A satisfação das crianças com a intervenção apontada em respostas dos escolares como: "Eu gostei do teatrinho, gostei mais do teatrinho" e "Eu gostei daqueles bonecos que mexiam e falavam", salientam a importância dos métodos lúdicoeducativos, como teatro de fantoches, jogos, cartilhas e paródias, como estratégias de veiculação de informações sobre alimentação e nutrição para crianças e adolescentes ${ }^{2,30}$.

Assim como o método é relevante para a efetividade da intervenção, Toral et al. ${ }^{31}$ apontam a importância de compreender as percepções do público alvo. Torna-se então necessário destinar um momento para as crianças relatarem suas percepções acerca da intervenção, tal como aqui realizado, constituindo uma oportunidade de analisar se as atividades propostas atenderam a demanda dos participantes, além de permitir o aprimoramento daquelas de menor aceitação (Quadro 3).

Quadro 3 - Principais respostas dos escolares sobre as limitações da intervenção realizada, Belo Horizonte-MG, 2011.

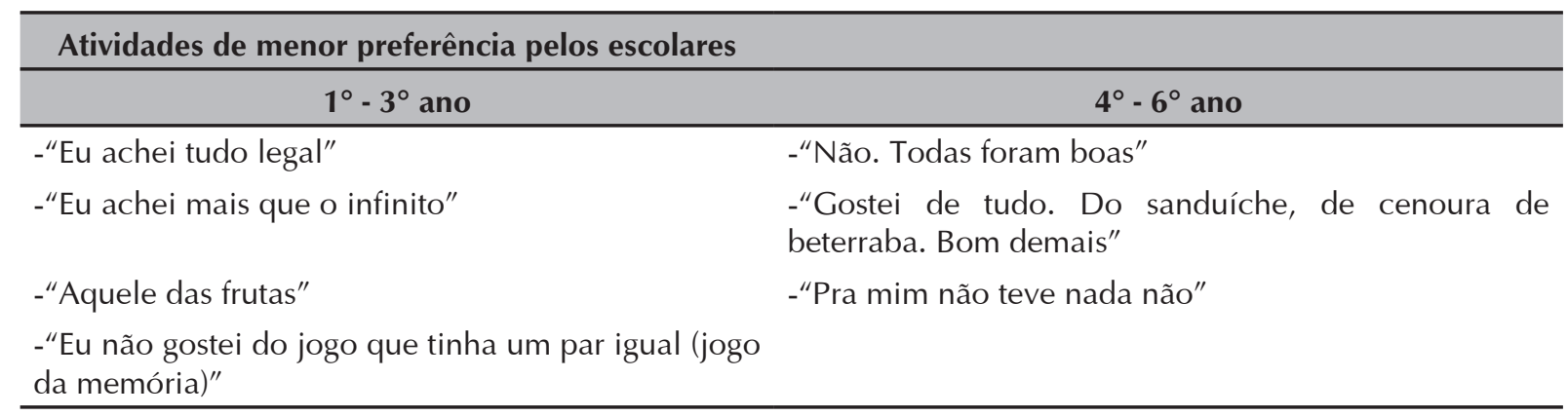


...continuação - Quadro 3

\section{Sugestões para trabalhos posteriores}

$$
1^{\circ}-3^{\circ} \text { ano }
$$

-"Eu queria que a gente fizesse, pegasse um livro na biblioteca pra gente que tivesse um grupo de comida"

-"Eu tenho quatro ideias. Contar história um macaquinho, eu queria que você fizesse mais coisa conosco"

-"Aquele lá dos botão. Jogar dama. Aquele de pescar... Você coloca cada fruta. Maçã, banana. Cada fruta, como chama aquela bolinha da dama? Cada fruta como pecinhas da dama. Ai a gente vai ter que pegar a fruta e falar o nome dela, da que tiver perto da gente"

-"E depois que acaba o jogo a gente pode comer"

-“E tem esse aqui também. Pega fruta também! Tipo tem uma cesta de fruta e ai você pega as frutas e você pega uma fruta boa, tipo a maçã, e ai pega a maçã e põe numa cestinha, quem pegar a maior quantidade de frutas ganha"

-"Pão de queijo (receitas)"

-"Legal é aquele negocio de colocar um vídeo. Que vocês colocaram. Eu não lembro. Que você pôs pra desenhar uma menina que estava sonhando. Tinha o macarrão, tinha os doces"

-"Mais músicas"

No presente estudo, a avaliação das atividades ocorreu quatro meses após a finalização da intervenção, o que pode ser considerado como uma possível limitação, uma vez que os participantes, dependentes da memorização, podem ter esquecido alguns conceitos trabalhados durante as atividades.

Entretanto, esse tempo também pode ser analisado de maneira positiva, já que permitiu identificar o que realmente foi aprendido pelas crianças e adolescentes tendo em vista o passar do tempo ${ }^{5}$.

Não há consenso na literatura acerca do tempo necessário para avaliação do aprendizado mas salienta-se que essa investigação também incluiu a avaliação da satisfação, que se torna um diferencial perante outros trabalhos.

Apesar dessa discussão pode-se inferir que as atividades de intervenção desenvolvidas de forma lúdica oportunizaram a construção de conhecimento sobre alimentação e nutrição entre as crianças e adolescentes, demonstrando a potencialidade dos programas deste tipo para a promoção de uma vida mais saudável desde a infância.

\section{CONCLUSÃO}

A elevada satisfação dos participantes com as ações realizadas denota interesse na aprendizagem de temas relacionados à alimentação e nutrição, bem como reforça a aplicabilidade desta temática no âmbito escolar.

Como o processo educacional é fruto de uma construção contínua, salienta-se a necessidade de atividades permanentes de educação alimentar e nutricional no projeto pedagógico, já que conhecimentos adequados sobre nutrição desde a infância são essenciais para o desenvolvimento de hábitos alimentares saudáveis.

Por fim, acredita-se que a riqueza das práticas educativas implementadas por meio do uso de atividades lúdico-didáticas pode favorecer a efetividade de intervenções, uma vez que permite aos participantes, de maneira 
descontraída e interativa, questionar, expor suas dúvidas e experiências e rever antigos conceitos, caracterizando-se como uma estratégia importante de promoção da saúde. Foi possível constatar que a utilização de jogos e dinâmicas, além do uso da música e do teatro oportunizaram a interação das crianças e maior adesão às atividades propostas. Tornase, portanto, essencial que as estratégias de educação alimentar nutricional privilegiam o cunho lúdico e a adequação às especificidades do público alvo.

AGRADECIMENTOS: À Fundação de Amparo à Pesquisa do estado de Minas Gerais (FAPEMIG) pelo financiamento do estudo (Processo: CDS - APQ-00013-09).

\section{REFERÊNCIAS}

1. Minossi V, Pelland LC. The "Happy Heart" educational program for changes in health habits in children and their families: protocol for a randomized clinical trial. BCM Pediatrics. 2015; 15:19.

2. Brasil. Brasil. Ministério do Desenvolvimento Social e Combate à Fome. Marco de referência de educação alimentar e nutricional para as políticas públicas. - Brasilia, DF: MDS; Secretaria Nacional de Segurança Alimentar e Nutricional, 2012. 68p.

3. Yokota RTC, Vasconcelos TF, Pinheiro ARO, Schmitz BAS, Coitinho DC, Rodrigues MLCF. Projeto "a escola promovendo hábitos alimentares saudáveis": comparação de duas estratégias de educação nutricional no Distrito Federal, Brasil. Rev Nutr. 2010; 23 : 37-47. 4. Gabriell CG, Santos MV, Vasconcelos FAG. Avaliação de um programa para promoção de hábitos alimentares saudáveis em escolares de Florianópolis, Santa Catarina, Brasil. Rev Bras Saúde Matern Infant. 2008; 8: 299-308.

5. Botelho LP, Zanirati VF, Paula DV, Lopes ACS, Santos LC. Promoção da alimentação saudável para escolares: aprendizados e percepções de um grupo operativo. Nutrire: rev Soc Bras Aliment Nutr. 2010; 35: 103-16.

6. Dantas OMS, Santana AR, Nakayama L. Teatro de fantoches na formação continuada docente em educação ambiental. Educação e Pesquisa. 2012; 38: 711-26.

7. Castro INR, Souza TSNS, Maldonado LA, Caniné ES, Rotenberg S, Gugelmin SA. A culinária na promoção da alimentação saudável: delineamento e experimentação de método educativo dirigido a adolescentes e a profissionais das redes de saúde e educação. Rev Nutr. 2007; 20: 571-88.

8. Fernandes PS, Bernardo CO, Campos RM, de Vasconcelos FA. Evaluating the effect of nutritional education on the prevalence of overweight/ obesity and on foods eaten at primary schools. J Pediatr. 2009; 85: 315-321.

9. Dudley AD, Cotton WG, Peralta LR. Teaching approaches and strategies that promote

healthy eating in primary school children: a systematic review and meta-analysis.International Journal of Behavioral Nutrition and Physical Activity. 2015; 12:28.

10. Prefeitura Municipal de Belo Horizonte [Internet]. Belo Horizonte amplia acesso à escola integrada. 2011 [acesso 2011 nov 01 ] Disponível em: <http://portalpbh.pbh.gov.br/pbh/ecp/contents.do?evento=conteudo\&idConteudo=479

06\&chPlc=47906\&termos=programa\%20escola\%20integrada $>$.

11. Brasil. Ministério da Saúde. Guia alimentar para a população brasileira: promovendo a alimentação saudável. Secretaria de Atenção à Saúde. Brasília: Ministério da Saúde; 2008.

12. Philippi ST, Latterza AR, Cruz ATR, Ribeiro LC. Pirâmide alimentar adaptada: guia para escolha dos alimentos. Rev Nutr. 1999; 12: 65-80.

13. Irala CH, Fernandez PM. A Escola promovendo hábitos alimentares saudáveis [Internet]. Brasília: Faculdade de Ciências da Saúde, Universidade de Brasília; 2001 [acesso 2011 nov 15]. Disponível: http://www.turminha.mpf.gov.br/para-o-professor/para-o-professor/ publicacoes/Caderno-de-atividades.PDF.

14. Brasil. Ministério da Saúde. Dez Passos para a Promoção da Alimentação Saudável nas Escolas [Internet]. Secretaria de Atenção à Saúde. Brasilia: Ministério da Saúde; 2006 [acesso 2011 nov 15]. Disponível em <http://189.28.128.100/nutricao/docs/geral/ dezPassosPasEscolas.pdf>.

15. Prefeitura Municipal de Belo Horizonte. Secretaria Municipal Adjunta de Abastecimento. Programa Educação Alimentar e Nutricional. Por dentro dos alimentos - A importância e a função dos nutrientes. Belo Horizonte, 2007.

16. Martinho LR, Talamoni JLB. Representações sobre meio ambiente de alunos da quarta série do Ensino Fundamental. Ciênc educ. 2007; 13: 1-13.

17. Campos CJG, Turato ER. Análise de conteúdo em pesquisas que utilizam metodologia clínico-qualitativa: aplicação e perspectivas. Rev Lat-Am Enfermagem. 2009; 17: 259-64.

18. Moraes R. Análise de conteúdo. Revista Educação. 1999; 22: 7-32.

19. Mendes R, Vaz A. Educação Ambiental no ensino formal: narrativas de professores sobre suas experiências e perspectivas. Educação em Revista. 2009; 25: 395-411.

20. Torres HC, Hortale VA, Schall V. A experiência de jogos em grupos operativos na educação em saúde para diabéticos. Cad Saúde Pública. 2003; 19: 1039-47.

21. Albuquerque AG, Pontes CM, Osório MM. Knowledge of educators and dieticians on food and nutrition education in the school environment. Rev. Nutr. 2013; 26: 291-300.

22. Council on School Health; Commitee on Nutrition. Snacks, sweetened beverages, added sugars, and schools. Pediatrics 2015; 135(3): 575-84.

23. Brasil. Ministério da Saúde. Secretaria de Atenção à Saúde. Departamento de Atenção Básica. Instrutivo PSE / Ministério da Saúde. Secretaria de Atenção à Saúde. Departamento de Atenção Básica.. - Brasília : Ministério da Saúde, 2011. 26p.

24. Rodrigues LPF, Roncada MJ. Educação nutricional no Brasil: evolução e descrição de proposta metodológica para escolas. Comun 
Ciênc Saúde. 2008; 19: 315-22.

25. Brasil. Ministério da Saúde. Secretaria de Atenção à Saúde. Departamento de Atenção Básica. Guia alimentar para a população brasileira / Ministério da Saúde, Secretaria de Atenção à Saúde, Departamento de Atenção Básica. - 2. ed. - Brasília: Ministério da Saúde, 2014. 156 p.

26. Grimm KA, Kim SA, Yaroch AL, Scanion KS. Fruit and vegetable intake during infancy and early childhood. Pediatrics 2014; 134 (Suppl. 1): S63-9.

27. Kaganov B, Caroli M, Mazur A, Singhal A, Vania A. Suboptimal micronutriente intake among children in Europe. Nutrients 2015; 13(7): 3524-3535.

28. He FJ, Wu Y, Feng XX, Ma J, Ma Y, Wang H, Zhang J, Yuan J, Lin CP, Nowson C, MacGregor GA. School based education programme to reduce salt intake in children and their families (School-EduSalt): cluster randomised controlled trial. BMJ 2015; 350:770. 29. Pérez-Rodrigo C, Aranceta J. School-based nutrition education: lessons learned and new perspectives. Publ Health Nutr. 2001; 4: 131-9.

30. Toral N, Conti MA, Slater B. A alimentação saudável na ótica dos adolescentes: percepções e barreiras à sua implementação e características esperadas em materiais educativos. Cad Saúde Pública. 2009; 25: 2386-94. 